\title{
Performance Analysis of the DigSILENT PV Model Connected to a Modelled Malaysian Distribution Network
}

\author{
Parthiban Perumal $^{1}$, Agileswari K. Ramasamy ${ }^{2}$ and Au Mau Teng ${ }^{3}$ \\ ${ }^{1,2,3}$ College of Engineering \\ ${ }^{1,2,3}$ Universiti Tenaga Nasional, Selangor Malaysia \\ parthiben7@gmail.com,agileswari@uniten.edu.my \\ Mtau@uniten.edu.my
}

\begin{abstract}
The global growth of Photovoltaic (PV) is remarkable with a total of $135 \mathrm{GW}$ in 2013 from $10 G W$ in 2007. Operation of $P V$ has changed from standalone to grid-connected which brings several challenges. This sudden spike in PV capacity is due to the reduced cost of PV modules over five times in last six years and followed by advancements in PV inverter technologies. Integration of distributed generation alters the unidirectional power system to bidirectional and alongside present's issues such as overvoltage on distribution feeders, overloading of feeders, and undesired exchange of reactive power. Traditional methods that are in practice to control the voltage and reactive power is by controlling the transformer tap changer and using capacitor banks. Volt-VAr control (VVC) activities by traditional methods are no longer appropriate due to intermittency solar irradiation caused by cloud transients. Modern PV inverter has the capabilities to mitigate voltage related issues when they are allowed to operate at power factor other than unity as stated in the IEEE1547-a. Germany and Spain are the pioneer countries in adopting 'smart' inverter operation in accordance with their countries interconnection grid guidelines. Similar operation of PV inverters for Malaysian scenario is prohibited as the current guideline does not allow the participation of PV inverters in voltage control activities. Therefore it is essential to allow the operation of smart inverter for Malaysian scenario, as the number of grid connected $P V$ system is on the rise. This paper extensively analyses the performance of the DigSILENT's PV model control aspects in terms of active power reduction and dynamic voltage support in a test network and validation of static voltage support on modelled Malaysian distribution network according to the new German Grid Code.
\end{abstract}

Keywords: Smart Inverter, Volt-VAr control, Malaysian distribution system

\section{Introduction}

According to the study carried out by the International Energy Agency (IEA) as a part of ongoing analysis on global renewable energy markets and policies, the involvement of ASEAN countries especially Malaysia in renewable energy sector is below the target and modification to existing legal framework and attractive tariff incentives can fix the situation [1]. Malaysia government's initiative to harness the potential of renewable energy started in 2001, when Small Renewable Energy Program was introduced. This programme is along with the government's effort of introducing Eight Malaysia Plan, where promoting renewable energy as fifth energy resource under the country's Fuel Diversification Policy. In this strategy, the energy mix in Malaysia is contributed by five main sources, namely natural gas, coal, oil, hydro and renewable energy. Introduction of renewable energy in Malaysia's energy mix had provided opportunity for government to reduce carbon intensity by $40 \%$ by 2020 [2]. 
The interconnection of Distributed Generation (DG) onto the distribution network brings additional challenges to the distribution network operators. Integration of distributed generation alters the unidirectional power system to bidirectional and alongside present's issues such as overvoltage on distribution feeders, overloading of feeders, and undesired exchange of reactive power. Voltage control in an active distribution network is an important aspects and this is usually achieved by Volt-VAr control (VVC). Traditional methods are in practice to control the voltage along the distribution system within the acceptable limits, achieved by the control of transformers tap changer and capacitor banks. These VVC dramatically changed over the years with the advancement in communication mode which helps in more coordinated control.

Centralized control requires wide range of communication system to coordinate different devices in the system such as OLTC and voltage regulator. On the other hand, decentralized control methods, able to control the DG unit locally in an active manner while coordinating with other devices. Local control methods are proved to improve the overall distribution network performance while keeping cost at minimum with limited need of communication system [3]. An innovative controller that coordinates the load tap changer (OLTC) action with the regulation of reactive exchanges between DG plants and feeder in an active network management is presented in [4]. The effectiveness of the proposed regulation is tested by applying to a realistic radial distribution network and the results proved that the capacity of DG's has significantly maintained the voltage profile in the system. Research efforts in [5] have been devoted in voltage control techniques of networks with distributed generation using On-load tap changer transformers. Operation of OLTC transformer equipped with automatic voltage control (AVC) relay is described in [6].

The centralized and decentralized VVC methods which are described on the earlier part of this section, are based on the control action of the distribution system regulating devices such as OLTC and capacitor banks. Mechanical based switching on low timescale of the conventional control methods are no longer appropriate due to intermittency solar irradiation caused by cloud transients. Modern PV inverter have the capabilities to mitigate voltage related issues when they are allowed to operate at power factor other than unity as stated in the IEEE1547-A (the changes in the interconnection standard has been described in Table 1).

This paper will focus on performance analysis of the DigSILENT PV model control aspects covering the active power reduction, dynamic voltage support and static voltage support according to the new German grid code. The DigSILENT PV model's active power reduction and dynamic voltage support controller action will be tested on the test network while the performance of the static voltage support carried out on the modelled Malaysian high density commercial network.

The rest of the paper organized as follows. Section 2 describes the new German Grid Code guideline. Section 3 describes the validity of the active power reduction and dynamic voltage support controller on test network. Section 4 analyses the performance of the static voltage support of the DigSILENT model on the modelled Malaysian commercial network topology. Section 5 includes conclusion and suggestions for future work.

\section{Review of Grid Interconnection Technical Guidelines}

First generations of PV inverters are designed to only operate at unity power factor as clearly stated on the IEEE-1547 Standard for Interconnecting Distributed Resources with Electric Power Systems [7]. Several research studies later suggests that the PV system can also contribute to voltage and reactive power control activities. This brings changes to the IEEE1547 grid interconnection guidelines where the new version of interconnection guideline clearly states that inverters are allowed to actively participate in voltage control activities. Similar strategy has been adopted in Germany with the introduction of German 
new grid code, to allow the active involvement of PV inverters in engaging voltage control activities.

The newly released grid code by the German Association of Energy and Water Industries (BDEW) [8] includes the guidelines for connecting power plants to the medium voltage (MV) power grid. The new German grid code now allows dynamic voltage support to provide voltage stability during the fault. The implementation of new grid code sets the generating power plant (PV plant) to perform following task; to stay connected during a fault, to support the voltage by providing reactive power during the fault and to consume the same or less reactive power after the fault clearance. The requirement of PV inverters to stay connected during fault is described in the Figure 1 below.

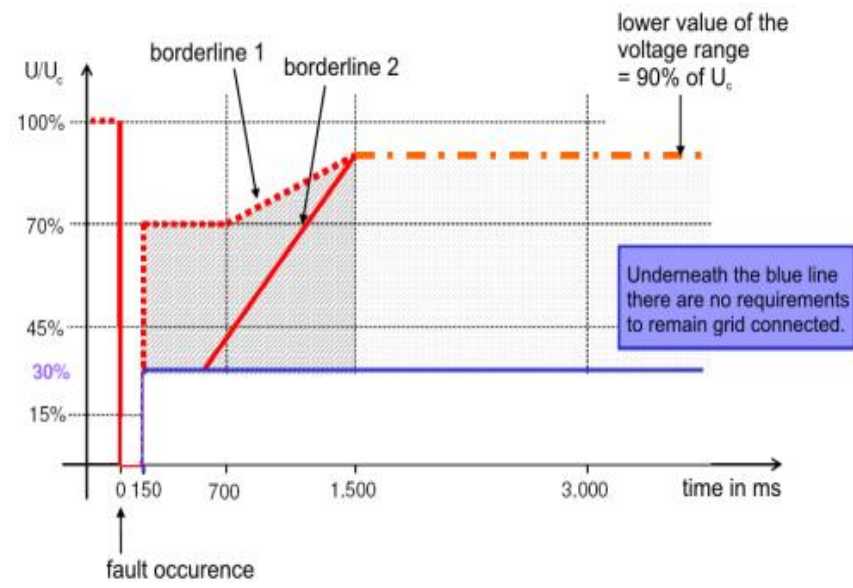

Figure 1. Limiting Curve to Remain Connected During Event of Fault

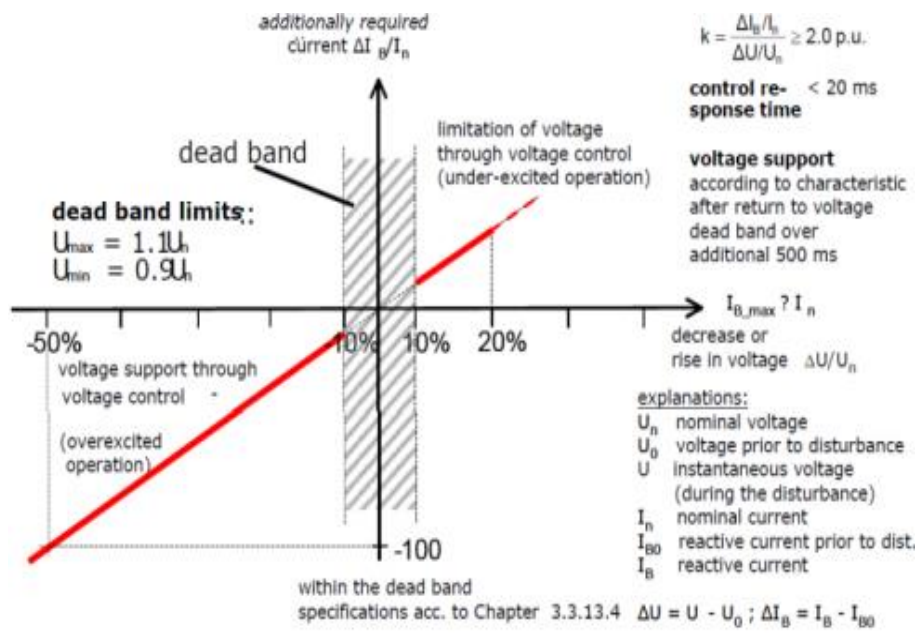

Figure 2. Voltage Support Requirement During Grid Faults

According to Figure 1, 4 different operation options are provided to the plant operator to ensure the steady operation of the system. Three operation region where the generating type must be connected and one operation region where the generating type can be disconnected are presented in the new grid code. For a voltage drop down to $0 \% U_{c}$ with duration of less than $150 \mathrm{~ms}$, the generating plant must be remain connected. Any voltage drop below 30\%, as marked blue in the Figure 1, the generator can be disconnected. Voltage dips below borderline 1 may not lead to disconnection or instability. Voltage dips above borderline 2 and below borderline 1 should be ridden through. Furthermore, the 
standard also states that, any voltage drop below borderline 2, short-time or longer time disconnection is also possible in any case.

The respective voltage support requirement is shown in Figure 2. The GC requires an injection of $90^{\circ}$ lagging current, depending on the minimum voltage. Nominal reactive current should be injected for faults having residual voltages of less than $50 \%$ of the $U_{c}$. Voltages in the normal operation area (dead band) do not require any dynamic voltage support characteristic.

Table 1. Changes in the IEEE Interconnection Guide

\begin{tabular}{|l|l|}
\hline IEEE 1547-2008 & IEEE 1547a-2014 \\
\hline $\begin{array}{l}\text { Shall not regulate } \\
\text { voltage }\end{array}$ & May participate in voltage regulation \\
\hline $\begin{array}{l}\text { Shall not regulate } \\
\text { frequency }\end{array}$ & May participate in frequency regulation \\
\hline $\begin{array}{l}\text { Restrictive voltage } \\
\text { and frequency } \\
\text { must-trip range }\end{array}$ & $\begin{array}{l}\text { More widely adjustable voltage and } \\
\text { frequency must trip range }\end{array}$ \\
\hline
\end{tabular}

\section{Test Setup Network to Validate the Controllers}

The performance of the DigSILENT PV model control aspects in terms of active power reduction and dynamic voltage support is tested on this part of the paper. $0.4 \mathrm{kV} 0.5 \mathrm{MVA}$ PV system of DigSILENT model is used to analyse the performance of the controller. The PV generator connected at 400V LV bus and is interconnected to the MV grid through a step up transformer as shown in Figure 3. The MV bus has a nominal voltage of $11 \mathrm{kV}$ and rated power of $0.5 \mathrm{MVA}$ and the windings are connected in DyN11 as illustrated on Figure 3 below. The short circuit power of the external grid is chosen to be 5MVA (ten times the PV capacity) in order to represent weak grid to facilitate the study of the reactive power influence on the

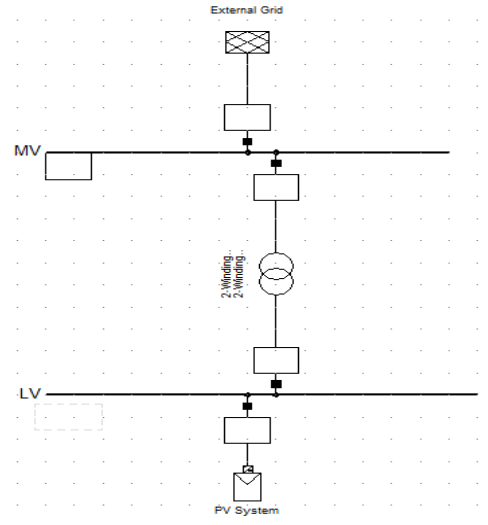
voltage support.

\section{Figure 3. The Test Network to Validate the Controllers}

\subsection{Control Aspects}

The generic PV template with additional features and control consists of multiple control blocks. The DC side of the model consists of three components, which are PV array, the DC bus and the capacitor. The solar radiation and temperature are two input components which enters the photovoltaic blocks and significantly effects the output power of the PV array. These two input parameters can be set by adjusting the output values $\mathrm{E}$ and theta respectively. These values then passed to the Photovoltaic model 
block, where the array current and voltage at MPP will be calculated according to the ideal solar cell equation. The AC side of the control frame equipped with all the basic requirements for a utility grid connected PV system to be compatible with German grid code. Active power curtailment based on measured frequency value on the grid is achieved with the help of frequency measurement device and active power reduction block.

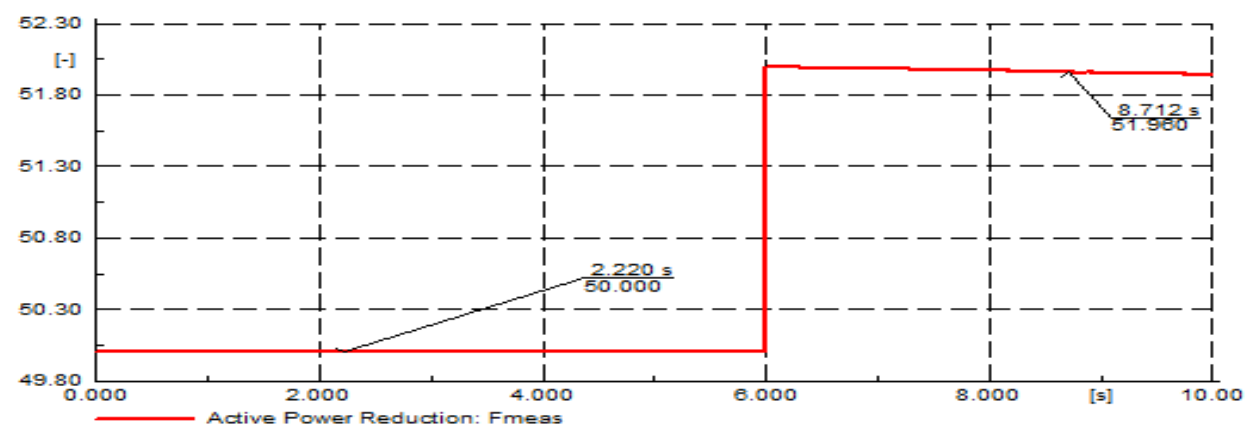

Figure 4 (a). The Control Frame of the DigSILENT PV Model

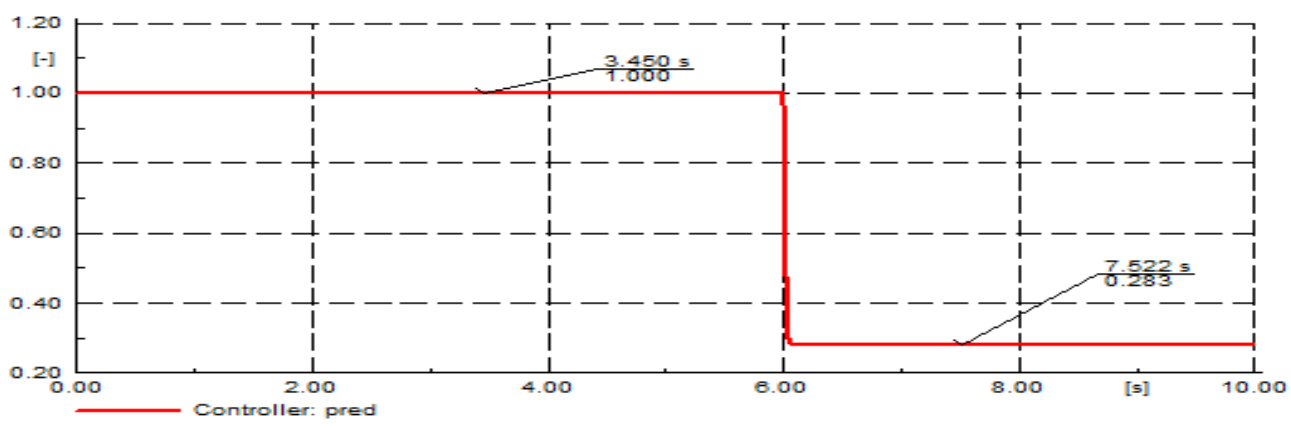

Figure 4 (b). Over Frequency Event

\subsection{Active Power Control}

Active power control refers to active power curtailment, the ability of the generating unit to produce its power output, as required by the network operator, sometimes also includes disconnection of PV plant to avoid grid stability issues. Frequency based active power control is implemented in the control block. German grid code sets the over frequency as any frequency above $50.2 \mathrm{~Hz}$ and a reduction slope of $40 \%$ is applied to bring back frequency to its nominal value. To investigate the validity of the active power controller, an over frequency event is created by changing the speed of the external grid at the $6^{\text {th }}$ second. The change of speed from 1p.u to 1.04p.u is sufficient enough to bring the frequency value to $52 \mathrm{~Hz}$ and for the active power reduction comes into play. The rise in frequency is plotted in the Figure 4 below. 


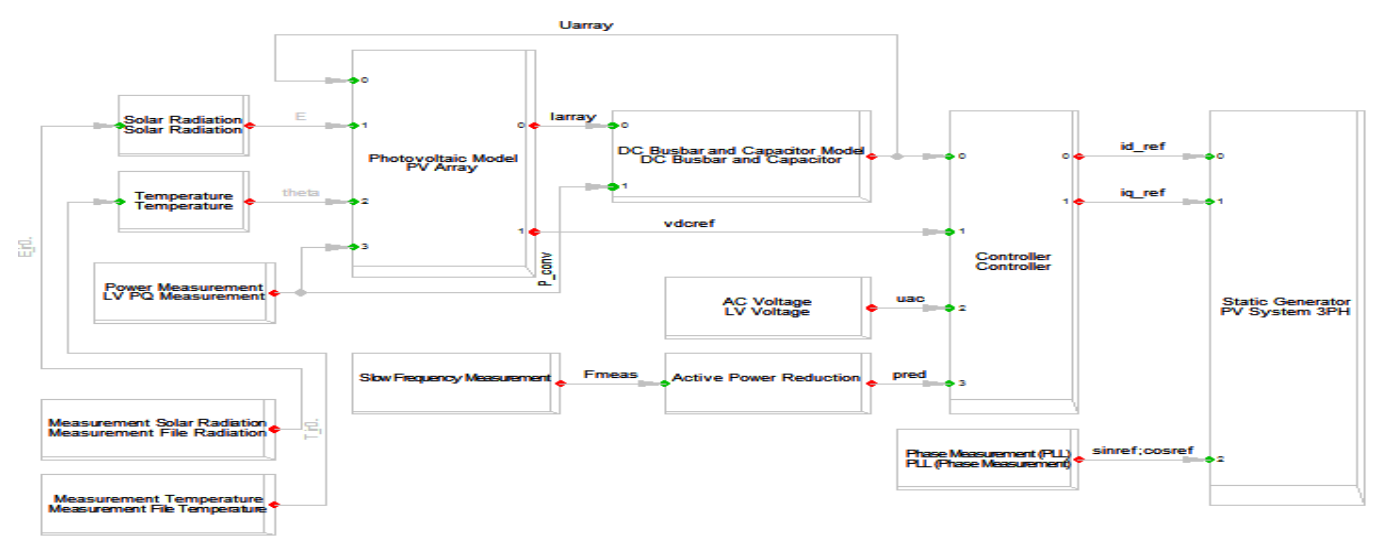

Figure 5. The Reduction in the Active Power of the PV Plant

The corresponding reduction on the active power of the PV generating plant can be seen from the Figure 5. The active power before the over frequency event (6th sec) is 1p.u. and after the over frequency event is 0.283 p.u marks the total reduction of $(71.7 \%)$. German grid code sets reduction slope of $40 \%$ of the last instantaneous power more than $50.2 \mathrm{~Hz}$. Reduction of active power during over frequency event based on reduction slope of $40 \%$ equals to $1.8 \mathrm{~Hz} \times 40 \%=72 \%$.Verification on the obtained value shows that the reduction follows the standard set by German Grid code.

\subsection{Dynamic Voltage Support}

German grid code has revised the interconnection standard whereby the local generating plants are required to support grid in case of fault oppose to what in practice in the past where the PV plant are advised to disconnect from the grid in occurrence of fault. This ability is also often referred as the low-voltage ride through (LVRT) capability where the PV generating plant support the grid up to several seconds by providing reactive power injection. The ride through ability varies depending on the amount and duration of voltage dip as stated earlier in Figure 1. To investigate the ride through ability of the generating PV plant, short circuit event has been created to simulate voltage dips. The different amount of voltage dips achieved by varying the fault impedance. Table 2 describes the different type of test performed to study the FRT behavior according to the new German grid code. The voltage support requirement has been already discussed in Figure 2.

Table 2. Different Test Performed for FRT Behaviour According to New German Grid Code

\begin{tabular}{|l|l|l|}
\hline Test & \multicolumn{1}{|c|}{$\begin{array}{c}\text { Maximum line-to-line } \\
\text { voltage }\end{array}$} & \multicolumn{1}{|c|}{$\begin{array}{c}\text { Duration of fault } \\
(\mathbf{m s})\end{array}$} \\
\hline 1 & 0 & 150 \\
\hline 2 & 0.2 & 550 \\
\hline 3 & 0.5 & 1000 \\
\hline 4 & 0.8 & 1500 \\
\hline
\end{tabular}

The result for test 1 performed on the simple network is presented in the Figure 6 . The MV voltage drops to 0 during fault, indicating pure short circuit fault, while before and after the fault remains at 0.999 p.u. The MV reactive power in the non-fault state is found to be -0.024 indicating the reactive power that being absorbed by the transformer.

Meanwhile, the voltage in the LV bus during the fault is $0.060 \mathrm{p} . \mathrm{u}$ and the voltage value 
before and after fault is close to its nominal value 0.999 p.u considering these values and based on Figure 2, the reactive current support during fault is;

$d u_{a c}=u_{a c}$ before fault $-u_{a c}$ during fault $=0.999-0.060=0.939$

By setting the droop parameter is set to 1 , the reactive current that is injected from the PV generator is $i_{q}=0.94$, which leads to;

$q_{\text {during fault }}=u_{\text {ac }}$ during fault $* i_{q}$ during fault $=0.060 * 0.94=0.0564$

This value is achieved by the controller as can be seen from the Figure 7, where 0.05 p.u of reactive power is injected during fault. The dynamic voltage support test has been repeated to test against different voltage dips and the results are presented below. The following information can be extracted based on the results displayed in the Table 3 . The injected amount of active power from the PV generator drops when the voltage drop becomes bigger. The reduction in the active power is to enhance the ability of the PV generator to provide voltage support by reactive power injection. The reactive current injection is bigger when the voltage dip is bigger, explains the capability of the PV inverter to support the voltage until the fault clearance. The response of the voltage support controller almost instant (less than $20 \mathrm{~ms}$ ) as per required by the grid code.

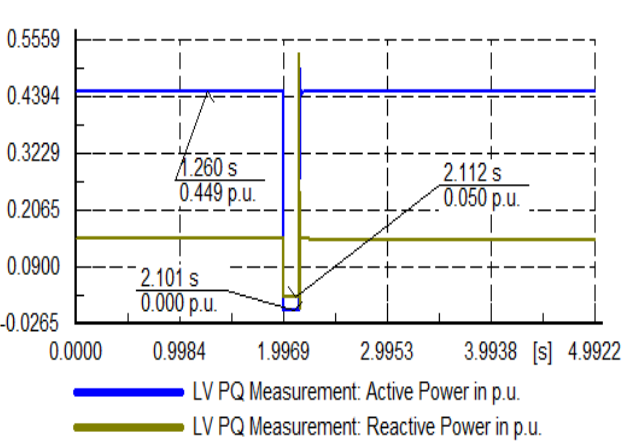

Figure 6. The MV and LV Voltages

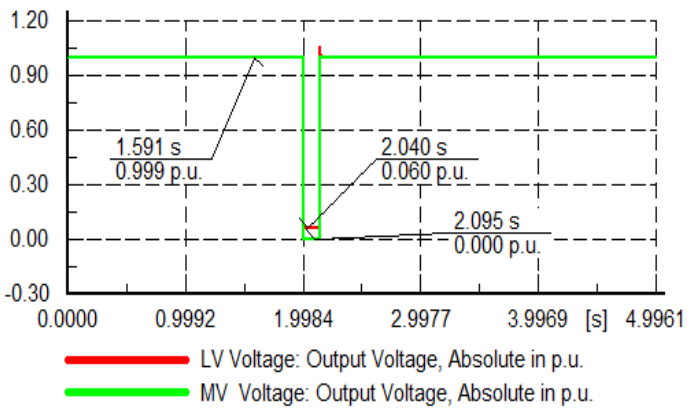

Figure 7. The Active and Reactive Power of the LV

Table 3. Aggregation of the Results for All Voltage Dips

\begin{tabular}{|c|c|c|c|c|}
\hline $\begin{array}{c}\text { Voltage dip } \\
(\mathbf{\%})\end{array}$ & $\begin{array}{c}\text { Voltage level } \\
\text { in } \\
\text { the LV bus } \\
\text { (p.u.) }\end{array}$ & $\begin{array}{c}\text { Injected } \\
\text { active power } \\
\text { by the PV } \\
\text { (p.u.) }\end{array}$ & $\begin{array}{c}\text { Injected } \\
\text { reactive } \\
\text { power by the } \\
\text { PV (p.u.) }\end{array}$ & $\begin{array}{c}\text { Injected } \\
\text { reactive } \\
\text { current by } \\
\text { PV (kA) }\end{array}$ \\
\hline $\mathbf{2 0}$ & 0.826 & 0.218 & 0.195 & 0.340 \\
\hline $\mathbf{5 0}$ & 0.742 & 0.134 & 0.237 & 0.460 \\
\hline $\mathbf{8 0}$ & 0.254 & 0.002 & 0.127 & 0.621 \\
\hline $\mathbf{1 0 0}$ & 0.060 & 0 & 0.030 & 0.722 \\
\hline
\end{tabular}

\section{Static Voltage Support on Modelled Malaysian High Density Commercial Network}

Malaysian distribution system compromises of three major network topologies which are commercial, residential and urban. A high density commercial network was modelled to investigate the adverse impacts of large-scale RE integration into the MV grid and the suitability of introducing smart inverter functionalities to participate in real and reactive power control. The PV system operating at unity power factor, considered to be normal operation for Malaysian scenario will be changed to power factor 0.95 to study the effect 
of the additional reactive power into the system. In addition to that, the existing static voltage support of the DigSILENT model will be tested against the modelled Malaysian commercial network.

City Centre and commercial district areas of major states of Malaysia, such as Kuala Lumpur, Selangor, Penang and Johor are all belongs to this type of network topology. Urban, high load density topology configuration usually are of double voltage transformation, with voltage level of $132 / 33 \mathrm{kV}$ and $33 / 11 \mathrm{kV}$. In this study, a medium voltage (MV) feeder selected from a substation considering the maximum length of feeder and maximum connected loads is modelled on DigSILENT. Three observation point, one at the start of the feeder, one in the middle of the feeder and one at the end of the feeder has been selected to investigate the effect of RE connection to the grid and also to study the contribution of smart inverter in participating on voltage control activities . The connection of solar PV is random, no prior study on the placement of PV has been carried out. Unity operation of PV generator is marked as a base case and the ability of PV generator to participate in static voltage support by means of fixed reactive power is discussed in this part of the paper. To achieve that, the PV inverters are usually oversized approximately $\mathrm{S}=1.1 P_{\max }$ so that in the case of maximum power generation, the $\mathrm{Q}$ requirement can be always achieved [9].

Total of $6 \mathrm{MW} \mathrm{PV}$ capacity is connected to the high density commercial network. The PV capacity connected at three different connection point of the high density commercial network which are at the start, middle and end of the feeder. Total of 6MW divided into three 2MW groups each connected to three different parts of the networks. The PV connection point are LV 101, LV 106 and LV 111 marked as red box in the Figure 8. Each red box represents four PV system connected in parallel, with each PV system with a size of $0.5 \mathrm{MVA}$ and unity power factor. The high density commercial network is modelled based on the details of the feeder following Table 4 . The Table 4 below includes the details of the primary circuit feeder such as the impedance and length of the lines. Total of 11 loads are connected at each terminals of the network. The loads are representation of the typical commercial load values and the loads are set at power factor of 0.9 .

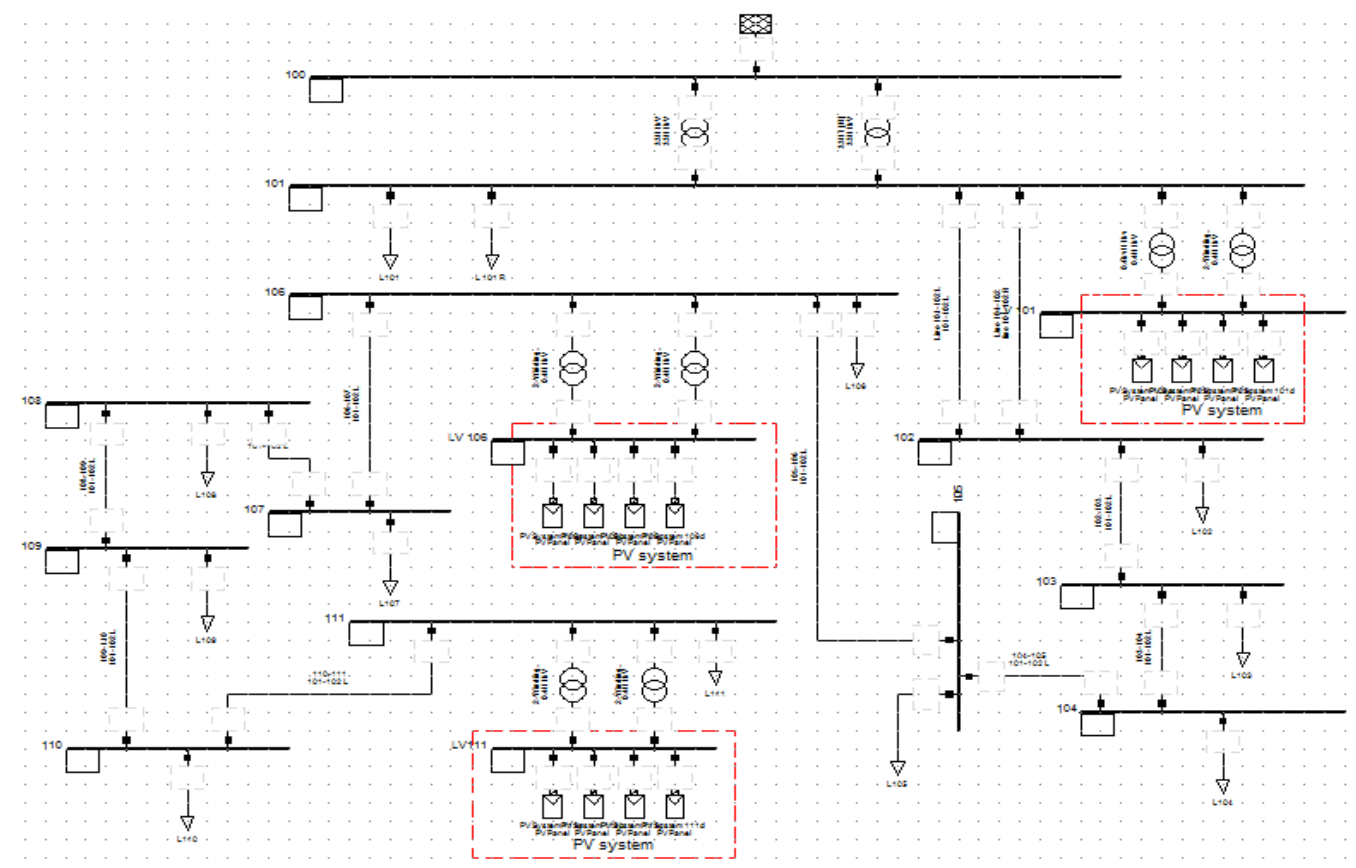

Figure 8. The Commercial Distribution Network Topology Modelled In Power Factory with Installed PV Capacity of 6MW 
Table 4. Description of the Primary Feeder Circuit Model

\begin{tabular}{|c|c|c|c|c|}
\hline $\begin{array}{l}\text { From } \\
\text { bus }\end{array}$ & $\begin{array}{l}\text { To } \\
\text { bus }\end{array}$ & Impedance & Length(km) & type \\
\hline 100 & - & & - & $\begin{array}{l}33 \text { kV Source; } \\
V=1.05 \text { p.u }\end{array}$ \\
\hline 100 & 101 & $10 \%$ & & $\mathrm{~T} 1,33 / 11 \mathrm{kV} 30 \mathrm{MVA}$ \\
\hline 101 & 102 & $\begin{array}{l}\mathrm{R}=0.08 \mathrm{ohm} ; \\
\mathrm{X}=0.0949 \mathrm{ohm}\end{array}$ & 1.5 & XA11UG500 \\
\hline 101 & 102 & $\begin{array}{l}\mathrm{R}=0.1609 \mathrm{ohm} ; \\
\mathrm{X}=0.1524 \mathrm{ohm}\end{array}$ & 0.6 & XA11UG240 \\
\hline 102 & 103 & $\begin{array}{l}\mathrm{R}=0.1609 \mathrm{ohm} ; \\
\mathrm{X}=0.1524 \mathrm{ohm}\end{array}$ & 1.1 & XA11UG240 \\
\hline 103 & 104 & $\begin{array}{l}\mathrm{R}=0.1609 \mathrm{ohm} ; \\
\mathrm{X}=0.1524 \mathrm{ohm}\end{array}$ & 0.5 & XA11UG240 \\
\hline 104 & 105 & $\begin{array}{l}\mathrm{R}=0.1609 \mathrm{ohm} \\
\mathrm{X}=0.1524 \mathrm{ohm}\end{array}$ & 0.6 & XA11UG240 \\
\hline 105 & 106 & $\begin{array}{l}\mathrm{R}=0.1609 \mathrm{ohm} \\
\mathrm{X}=0.1524 \mathrm{ohm}\end{array}$ & 1.2 & XA11UG240 \\
\hline 106 & 107 & $\begin{array}{l}\mathrm{R}=0.1609 \mathrm{ohm} ; \\
\mathrm{X}=0.1524 \mathrm{ohm}\end{array}$ & 0.5 & XA11UG240 \\
\hline 107 & 108 & $\begin{array}{l}\mathrm{R}=0.1609 \mathrm{ohm} ; \\
\mathrm{X}=0.1524 \mathrm{ohm}\end{array}$ & 0.7 & XA11UG240 \\
\hline 108 & 109 & $\begin{array}{l}\mathrm{R}=0.1609 \mathrm{ohm} ; \\
\mathrm{X}=0.1524 \mathrm{ohm}\end{array}$ & 1.0 & XA11UG240 \\
\hline 109 & 110 & $\begin{array}{l}\mathrm{R}=0.1609 \mathrm{ohm} ; \\
\mathrm{X}=0.1524 \mathrm{ohm}\end{array}$ & 0.8 & XA11UG240 \\
\hline 110 & 111 & $\begin{array}{l}\mathrm{R}=0.1609 \mathrm{ohm} \\
\mathrm{X}=0.1524 \mathrm{ohm}\end{array}$ & 0.8 & XA11UG240 \\
\hline
\end{tabular}

\subsection{Test Case Scenario}

The DigSILENT PV model is tested for its static voltage support capabilities on the modelled Malaysian distribution commercial network on this part of the paper. In order to analyse the effect of operating PV model at 0.95 and the models capability to perform static voltage support, several case studies are included as follows;

Case 1: Grid with only load without PV connection: This case study acts as a base case and particularly important to study the voltage level at every terminals at normal operation of the grid with no connection of PV generators.

Case 2: Grid with PV integration at unity power factor: The connected PV models are set to operate at unity power factor similar to current operation of PV system in Malaysia. The effect of PV system in terms of voltage rise and reverse power flow is examined.

Case 3: Grid with PV integration at 0.95 power factor: The PV models are set to operate at $0.95 \mathrm{PF}$ enabling the PV models to inject reactive power into the system. The PV models static voltage support capability is examined.

\section{Results}

The effect of connecting PV system to the existing distribution network in terms of voltage rise is presented in the Table 6 below. The voltage limits at normal operation are within the MV grid limits as suggested by the Malaysian distribution network which is $33 / 11 \mathrm{kV} \pm 5$. The integration of PV system at unity pf and corresponding voltage rise is also tabulated and presented as case 2 in the Table 6 below. As expected, the voltage rise 
is visible at every network and the rise is highest at the PV connection terminal and also at the terminals after/ before the PV connection as the reverse power flow causes the voltage rise at the respective terminals.

Table 6. The Voltage Levels Before and After the Connection of PV System

\begin{tabular}{|c|c|c|c|}
\hline \multicolumn{2}{|l|}{} & \multicolumn{2}{l|}{ Bus voltage (p.u) } \\
\hline Terminal & $\begin{array}{l}\text { Rated } \\
\text { voltage (kV) }\end{array}$ & $\begin{array}{l}\text { Before } \\
\text { PV } \\
\text { (Case 1) }\end{array}$ & $\begin{array}{l}\text { After } \\
\text { PV } \\
\text { (Case 2) }\end{array}$ \\
\hline 100 & 33 & 1.05 & 1.05 \\
\hline 101 & 11 & 1.022 & 1.023 \\
\hline 102 & 11 & 1.017 & 1.019 \\
\hline 103 & 11 & 1.008 & 1.015 \\
\hline 104 & 11 & 1.004 & 1.014 \\
\hline 105 & 11 & 0.999 & 1.012 \\
\hline 106 & 11 & 0.992 & 1.01 \\
\hline 107 & 11 & 0.989 & 1.009 \\
\hline 108 & 11 & 0.986 & 1.008 \\
\hline 109 & 11 & 0.984 & 1.008 \\
\hline 110 & 11 & 0.983 & 1.009 \\
\hline 111 & 11 & 0.983 & 1.01 \\
\hline LV 101 & 0.4 & 1.022 & 1.022 \\
\hline LV 106 & 0.4 & 0.992 & 1.01 \\
\hline LV 111 & 0.4 & 0.983 & 1.009 \\
\hline
\end{tabular}

The integration of PV system into distribution system causes reverse power flow, where bidirectional power flow is observed as can be seen from the Figure 9 below. The black direction arrow represents the flow of the power in the modelled distribution network and the reverse power flow is present at the terminal 106.

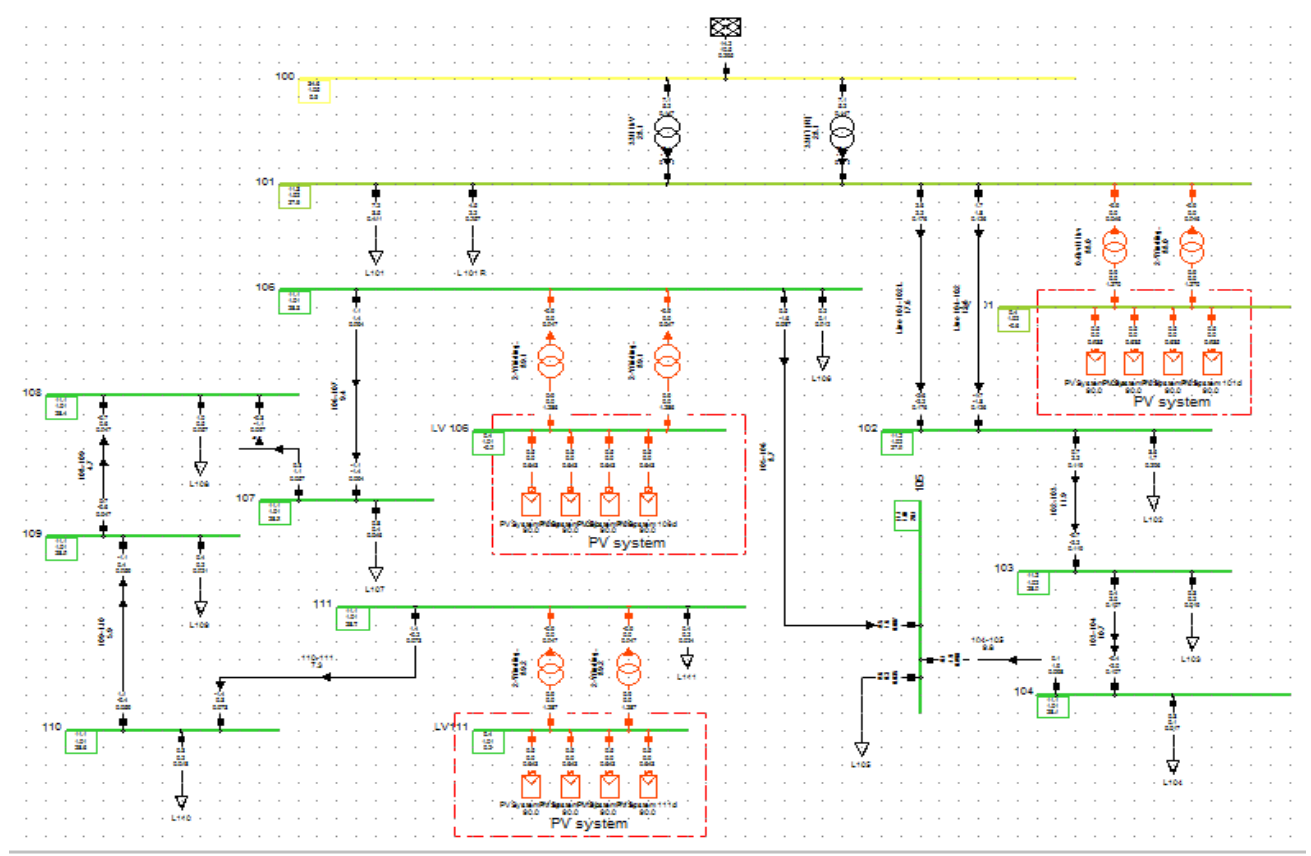

Figure 9. The Bidirectional Power Flow 


\subsection{PV System Operating at Unity Power Factor}

The PV generators connected to the high density commercial network are initially operated at unity power factor with no injection of reactive power into the system. The active power of the every single PV generator set to $0.449 \mathrm{MW}$. Multiple PV generators are connected to make a group of PV system which injects $2 \mathrm{MW}$ at respective terminal which is the maximum allowed value at a single feeder by the Malaysian guidelines. Irradiance drop at the $5^{\text {th }}$ second is set to study the behaviour of active and reactive power at the PCC. The corresponding behaviour of the PV generator in terms of active, reactive power and power factor are plotted as shown by Figure 10 below.

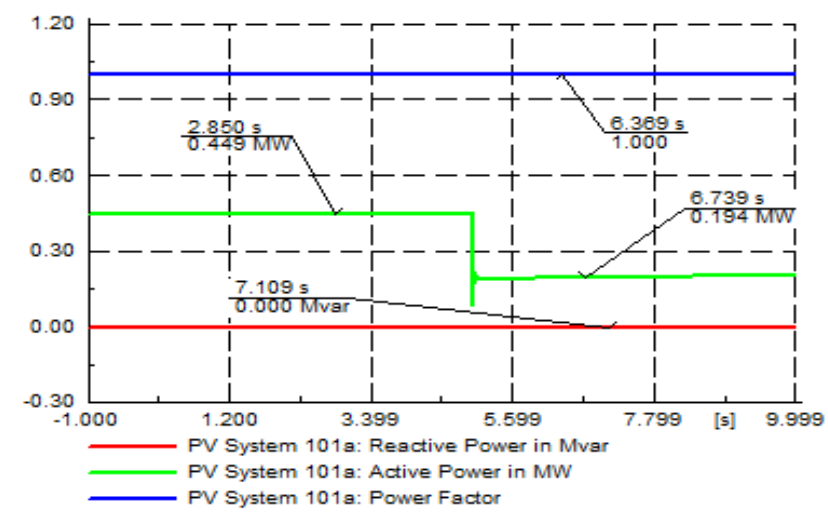

Figure 10. The Behaviour of PV System at Unity PF

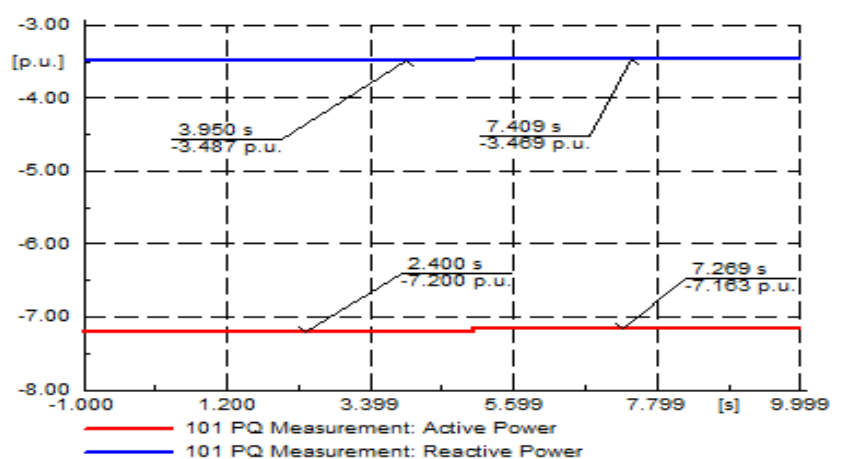

Figure 11. The Active and Reactive Power at the PCC

As expected the reactive power is zero, throughout the simulation period of $10 \mathrm{~s}$. The active power of the PV generator drops to $0.194 \mathrm{MW}$, reduction of almost $43 \%$ at the $5^{\text {th }}$ sec. Power factor of the PV generator remains unity despite the reduction in the active power. Active and reactive power behaviour at the PCC is plotted and shown in Figure 11.

\subsection{PV System Operating At 0.95 Power Factor}

The ability of the PV system's built in static voltage support controller will be validated to provide voltage support to control the system's reactive power under fixed Q discussed in this part of the paper. In order to study the validity of the controller to provide static voltage support the existing PV generators input mode will be changed to PQ mode as this makes the PV generator are usually designed for bigger size so that in the case of maximum active power generation, the $\mathrm{Q}$ requirement can always be achieved. The expected result will be that with the drop in active power due to irradiance effect, the reactive power reduces as well in order to maintain the fixed power factor. 


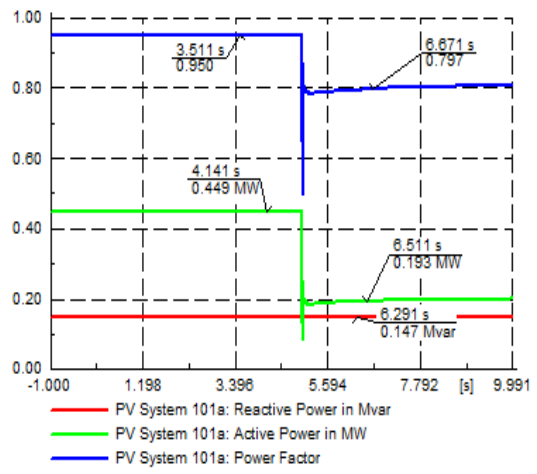

\section{Figure 12. The Behaviour of PV System Operating at 0.95PF}

The irradiance drop was set at $5^{\text {th }} \mathrm{sec}$ and the accordance drop in the active power is shown in Figure 12 . The active power drop is nearly $43 \%$ to a value of $0.193 \mathrm{MW}$. The reactive power is observed to be the same throughout the simulation period of 10s. This shows the current PV controller action lacks of static voltage support. The power factor of the PV generator is also not regulated as the power factor is out of the permitted limit which is \pm 0.95 .

\section{Future Works}

The future study will focus on developing the static voltage support based on Q (U) droop characteristics. Q (u) droop characteristics are more favourable strategy as this control method allows the inverter to monitor its own terminal voltage and respond with a custom VAr response determined by the local utility. The involvement of PV inverter participating in voltage control activities truly makes it 'smart' and that is something needed for Malaysian distribution network as the grid connected PV system is on the rise.

\section{Conclusion}

Intermittent nature of PV generator brings additional challenges to the DNO in terms of Voltage-VAr control (VVC). The traditional method of voltage controls by means of OLTC and capacitor banks are inappropriate with rapidly changing solar irradiation. The 'smart inverter' term is coined lately which describes the ability of PV inverter to actively participate in VVC activities. This study investigates the controller ability to provide active power reduction and dynamic voltage support tested on test network in the first paper of the paper. Second part of the paper deals with the validity of the DigSILENT PV model to provide static voltage support by means of fixed reactive power dispatch on the modelled Malaysian high density commercial network. Provided simulation results shows that the existing controller lacks the static voltage support mechanism and future study will consider this drawback. Therefore, allowing the PV inverter to participate in voltage control activities following countries like Germany and Spain promises better future for penetration of renewable energy into distribution network for tropical country like Malaysia, which receives solar radiation throughout the year. 


\section{References}

[1] S. Ölz and M. Beerepoot, "Deploying renewables in Southeast Asia: Trends and potentials", (2016).

[2] Energy Commission, "Peninsular Malaysia Electricity Supply Industry Outlook 2013, Malaysia", (2013).

[3] M. Begović, A. Pregelj, A. Rohatgi and D. Novosel, "Impact of renewable distributed generation on power systems", 34th annual Hawaii international conference on system sciences (HICSS-34)-Volume 2, Maui, Hawaii January 03-January 06.

[4] F. Bignucolo, R. Caldon and V. Prandoni, "Radial MV networks voltage regulation with distribution management system coordinated controller", Electric Power Systems Research, vol. 78, Issue 4, (2008), pp. 634-64

[5] C.A. Smith and M.A. Redfem, "Improvement in the Performance of On load Tap Changer Transformers Operating in Series", IEEE Power Engineering Society General Meeting, Toronto, Canada, 13-17 July, (2003).

[6] C. Gao and M. A. Redfern, "A review of voltage control techniques of networks with distributed generations using On-Load Tap Changer transformers", In Universities Power Engineering Conference (UPEC), 2010 45th International, IEEE, (2010), pp. 1-6.

[7] ISC Committee, "IEEE standard for interconnecting distributed resources with electric power systems", New York, NY: Institute of Electrical and Electronics Engineers, (2003).

[8] BDEW, June, "Technical Guideline Generating PlantsConnected to the medium-Voltage Network”, BDEW, Berlin, Germany, (2008).

[9] Marinopoulos and Antonios, "Grid integration aspects of large solar PV installations: LVRT capability and reactive power/voltage support requirements", PowerTech, 2011 IEEE Trondheim. IEEE, (2011). 
International Journal of Control and Automation

Vol. 9, No. 12 (2016) 